\title{
Meteorological effects in the lower ionosphere as based on VLF/LF signal observations
}

\author{
A. Rozhnoi ${ }^{1}$, M. Solovieva ${ }^{1}$, B. Levin ${ }^{2}$, M. Hayakawa ${ }^{3}$, and V. Fedun ${ }^{4}$ \\ ${ }^{1}$ Institute of Physics of the Earth, Russian Academy of Sciences, Moscow, Russia \\ ${ }^{2}$ Institute of Marine Geology and Geophysics, Far East Branch of Russian Academy of Sciences, Yuzhno-Sakhalinsk, Russia \\ ${ }^{3}$ University of Electro-Communications, Advanced Wireless Communications Research Center, Chofu Tokyo, Japan \\ ${ }^{4}$ Department of Automatic Control and Systems Engineering, University of Sheffield, Sheffield, UK
}

Correspondence to: A. Rozhnoi (rozhnoi@ifz.ru)

Received: 16 February 2014 - Published in Nat. Hazards Earth Syst. Sci. Discuss.: 24 April 2014

Revised: - - Accepted: 3 September 2014 - Published: 1 October 2014

\begin{abstract}
Very low and low frequency (VLF/LF) data recorded in the Far Eastern stations PetropavlovskKamchatsky $\left(158.92^{\circ} \mathrm{E}, \quad 53.15^{\circ} \mathrm{N}\right)$, Yuzhno-Sakhalinsk $\left(142.75^{\circ} \mathrm{E}, 46.95^{\circ} \mathrm{N}\right)$ and Yuzhno-Kurilsk $\left(145.861^{\circ} \mathrm{E}\right.$, $44.03^{\circ} \mathrm{N}$ ) are investigated to study the meteorological effects in the lower ionosphere. The results demonstrate the sensitivity of the VLF/LF signals to the variations of atmospheric pressure, humidity, wind velocity and temperature, and the VLF/LF record at the station of Yuzhno-Kurilsk is found to be most sensitive to those variations of atmospheric parameters. The region under consideration is characterized by high winter cyclonic activity in mid-latitudes and strong summer and autumn typhoon activity in low latitudes. VLF/LF signal variations during eight tropical cyclones (TCs) with different intensity are considered. Negative nighttime anomalies in the signal amplitude that are most probably caused by TC activity are found for six events. Those anomalies are observed during 1-2 days when TCs move inside the sensitivity zones of the subionospheric paths. Perturbations of the VLF signal observed during two TCs can be caused by both the TC influence and seismic activity, but no correlation between TC intensity and magnitude of the signal anomalies is found. Spectral analysis of the typhoon-induced disturbed signals revealed the fluctuations with time periods in the range of 7-16 and 15-55 min that corresponds to the range of internal gravity waves periods.
\end{abstract}

\section{Introduction}

The method of VLF/LF $(15-50 \mathrm{kHz})$ radio sounding of the upper atmosphere and lower ionosphere (with the purpose of studying ionospheric disturbances caused by earthquakes, tsunami or volcano eruptions, which is the main aim of our work) requires knowledge of VLF/LF signal variations related to other forcing. The behaviour of the VLF/LF signals is dependent not only on magnetic and solar activities (e.g. proton and X-ray flashes, electron fluxes, zenith angle of the sun), but also on the meteorological characteristics of the lower atmosphere.

Meteorological effects in the ionosphere have been studied for a long time. The strongest disturbances in the ionosphere can be caused by cyclones and especially by tropical cyclones (TCs), which are termed hurricanes in America and typhoons in the Far East and Southeast Asia. Beginning with the work of Bauer (1958), the response in $F$ region of the ionosphere to the passage of TCs was reported in a great number of papers. The fluctuations in the foF2 (critical frequencies of the $F 2$ layer that corresponds to the maximum radio frequency that can be reflected by this region of the ionosphere at vertical incidence) were found as a typhoon is approached (Shen, 1982; Liu et al., 2006). Tao et al. (2010) concluded that typhoons caused a short increase in foF2 before the landing and a persistent decrease after landing. The effects of typhoon Matsa on the ionosphere were studied by Mao et al. (2010) using TEC (Total Electron Content) data observed at about 50 GPS stations. They found that the evolution of TEC variations had the same tendency as 
the typhoon-induced foF2. A change in foF2 parameters in connection with TC activity was analysed based on the latitude in Vanina-Dart et al. (2011). It was then shown that the character of ionospheric variations depended on the stage and spatio-temporal state of TC and on the distance between the TC centre and point of the ionosphere measurements. Such a TEC-GPS method of ionospheric disturbance detection was used recently in many other works relating to TC studies (e.g. Bishop and Straus, 2006; Xu et al., 2008; Lin, 2012; Zakharov and Kunitsyn, 2012; Polyakova and Perevalova, 2011). In the last work, ionospheric response was estimated on the example of three TCs - Katrina, Rita, and Wilma near the US Atlantic coast. Maps of TEC disturbances in two periods of ranges (2-20 and 20-60 min) were compared with those of meteorological parameters. An increase in TEC variations was revealed when TCs reached their peak intensity. Those authors concluded that the radius of the region of ionospheric plasma irregularities is about $2000 \mathrm{~km}$ and disturbances with longer periods covered a larger area.

The ionospheric response to typhoons was also found from a case study and statistical analysis of HF Doppler shift data (Huang et al., 1985; Z. Xiao et al., 2007; S. Xiao et al., 2007, 2012). In some papers, those authors found the possible response of TCs even in the topside ionosphere from Cosmos1809 and Intercosmos 24 satellite observations (Mikhailova et al., 2000; Isaev et al., 2002, 2012).

The experimental data may be explained in terms of the upward propagation of a broad spectrum of internal gravity waves (IGWs), tides and planetary waves (see a review by Kazimirovsky, 2002). The possible sources of these waves, problems of their generation, propagation, dissipation and influence on the ionosphere plasma parameters are widely discussed at present. A version of the physical mechanism of rapid interactions between tropospheric disturbances and the ionospheric response based on typhoon-generated acoustic waves and IGWs, which is dependent on the temperature and wind structure in the atmosphere, was proposed in many publications, including the papers cited above.

Atmosphere acoustic and gravity waves are considered as a key factor in the dynamics and energy of the atmosphereionosphere coupling in Sharkov (2012). IGW activities were investigated in the lower stratosphere during the typhoon passage using the MU radar (Dhaka et al., 2003). Dominant gravity waves showed time periods in the range of $7-8,15$, and 40-60 min. Perevalova and Polekh (2009) confirmed the hypothesis of IGW as a possible physical mechanism of the interaction between the troposphere and ionosphere on the basis of the analyses of data of the vertical sounding of the upper atmosphere in the Pacific region.

An alternative theory of atmosphere-ionosphere coupling is based on the influence of the electric field induced by TCs (e.g. Pulinets et al., 2000; Bondur and Pulinets, 2012; Sorokin et al., 2006). Troposphere-ionosphere coupling is explained by the penetration in the ionosphere of the electric field from the electric charge formed at the top of a TC as a result of the convection intensification. This leads to the increase of electron concentration in the $F$ layer maximum over the TC center. Bondur et al. (2008), using TEC data, revealed an increase in the electron concentration at the $F 2$ layer maximum during the passage of the TC Katrina, and the maximum of the electron concentration corresponded to the decrease of the $F 2$ layer altitude by several kilometres above the TC. The ionospheric disturbances were found to coincide in time with the maximum outgoing longwave radiation flux generated at the hurricane top as well. Those authors concluded that such observed effects are due to the penetration into the ionosphere of the vertical electric field generated by the TC.

All of the methods and observations described above relate mostly to the upper ionospheric response during the passage of TCs. It is possible that the lower D region of the ionosphere can be more influenced by the processes in the troposphere, so the effects of TCs in the lower ionosphere have been studied by in situ mode such as rocket sounding of the equatorial D region (e.g. Sharkov, 2012). However, measurements with the use of rockets are very transient and spatially limited. Undoubtedly, the most suitable for the study of meteorological effects upon the $\mathrm{D}$ region are ground-based VLF/LF observations, because they provide data records continuous in time. The VLF/LF signals reflect from the lower ionosphere $(\sim 60 \mathrm{~km}$ in the daytime and $\sim 85 \mathrm{~km}$ at night) and any changes in plasma density in this region influence VLF/LF properties. The only anomaly in VLF/LF signals which was likely to be associated with a strong TC was reported by Hayakawa et al. (2008) in analysing the ionospheric perturbations associated with the 2007 Niigata Chuetsu-oki earthquake.

The aim of this work is to investigate the variations of VLF/LF signals associated with the meteorological factors. The analysis made previously for the LF $(40 \mathrm{kHz})$ signal recorded in Petropavlovsk-Kamchatsky and several Japanese stations has shown a sensitivity of the LF signal to variations of atmospheric pressure (Rozhnoi et al., 2006). The recent development of the VLF/LF network in the Far East region with the purpose of searching electromagnetic precursors of earthquakes as well as for the study of the lower ionosphere response to tsunami and volcano eruptions, can be utilized for the further investigations of VLF/LF variations in connection with the troposphere circulation. This problem is very important for this region with extensive cyclonic activity, especially in winter in mid-latitudes and strong typhoons in summer and autumn in low latitudes.

\section{Data analysis and results}

We have used data from three stations, sited in the Russian Far East - Petropavlovsk-Kamchatsky (PTK, $158.92^{\circ}$ E, $\left.53.15^{\circ} \mathrm{N}\right)$, Yuzhno-Sakhalinsk $\left(\mathrm{YSH}, 142.75^{\circ} \mathrm{E}, 46.95^{\circ} \mathrm{N}\right)$ and Yuzhno-Kurilsk $\left(\mathrm{YUK}, 145.861^{\circ} \mathrm{E}, 44.03^{\circ} \mathrm{N}\right)$ in this 


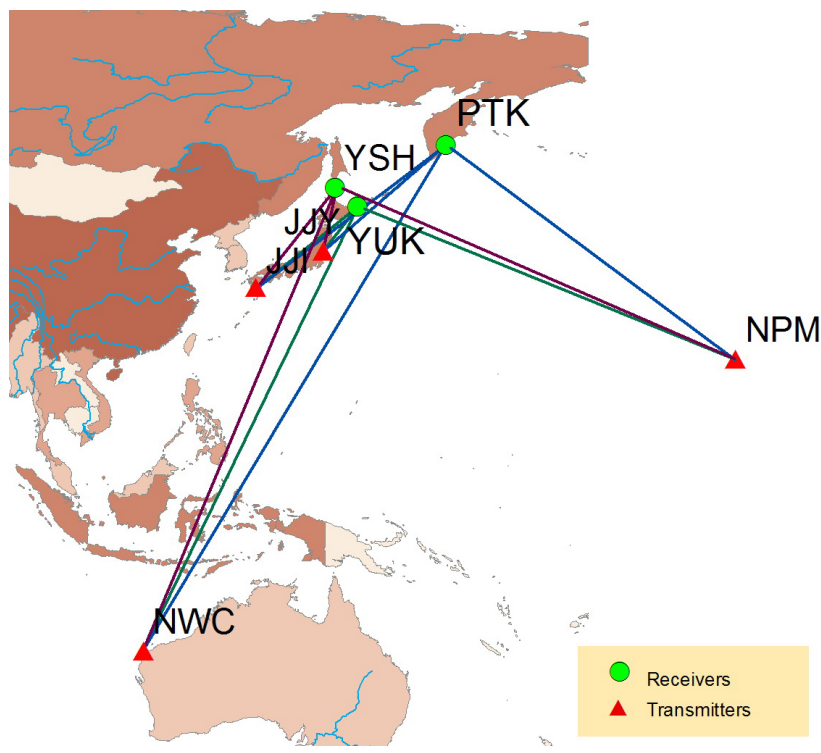

Figure 1. A map showing the position of the receivers in Petropavlovsk-Kamchatsky (PTK), Yuzhno-Sakhalinsk (YSH) and Yuzhno-Kurilsk (YUK), together with the position of the transmitters JJI $(22.2 \mathrm{kHz})$, JJY $(40 \mathrm{kHz}), \mathrm{NWC}(19.8 \mathrm{kHz})$ and NPM $(21.4 \mathrm{kHz})$.

work. The position of the receiving stations and four of the VLF/LF transmitters are shown in Fig. 1. All the stations are equipped with the identical receivers that register simultaneously the amplitude and phase of MSK (minimum shift key) narrowband modulated signals in the frequency range of 10 $50 \mathrm{kHz}$ from several transmitters. The reception is carried out by electric rod antenna. It measures the electric vertical component of the electromagnetic field. The receiver can record signals with time resolutions ranging from $50 \mathrm{~ms}$ to $60 \mathrm{~s}$. For our purpose we use a sampling frequency of $20 \mathrm{~s}$. Only the amplitudes of VLF/LF signals, for which we do not need any preprocessing, are analysed in this paper. For our analysis we use a residual signal of amplitude calculated as the difference between the real signal and the monthly averaged signal. Since VLF signals are very stable during the daytime and unaffected by any forcing except by X-rays emitted during solar flares, the analysis was made only for nighttime.

The PTK receiving station was installed in 2000 , and the new receivers with online access to data were put into operation in 2009 in YSH and in 2011 in YUK. The PTK station can register signals from only four transmitters: NWC $(19.8 \mathrm{kHz})$ in Australia $\left(114.16^{\circ} \mathrm{E}, 21.81^{\circ} \mathrm{S}\right)$, NPM $(21.4 \mathrm{kHz})$ on the Hawaiian Islands $\left(158.15^{\circ} \mathrm{W}, 21.42^{\circ} \mathrm{N}\right)$, JJI $(22.2 \mathrm{kHz})$ in Kyushu, Japan $\left(130.83^{\circ} \mathrm{E}, 32.08^{\circ} \mathrm{N}\right)$ and $\mathrm{JJY}(40 \mathrm{kHz})$ in Honshu, Japan $\left(140.85^{\circ} \mathrm{E}, 37.37^{\circ} \mathrm{N}\right)$. These signals are analysed at every station in this work. In addition to these signals, the new stations register signals from another four transmitters: NAA $(24.0 \mathrm{kHz})$ in Maine, USA, NLK $(24.8 \mathrm{kHz})$ in the state of Washington USA, NTS
$(18.6 \mathrm{kHz})$ in the east coast of Australia and VTX $(18.2 \mathrm{kHz})$ in the south of India.

\subsection{Correlation with meteorological parameters}

We apply a correlation method to examine the sensitivity of the VLF/LF signals to the change of meteorological factors. We correlate the residual amplitude of the signals averaged over nighttime and daily average data series on atmospheric pressure, humidity, wind velocity and temperature recorded in the local weather stations (http://rp5.ru/) for 2012. At the PTK receiving station a clear correlation with all meteorological factors was found only for the JJY signal that confirms previously obtained results. The correlation at YSH station with pressure, wind velocity and temperature was revealed only for the JJI signal. However, at YUK station we have discovered a correlation with all the parameters and for all the signals. Figure 2 shows two examples of cross-covariance functions calculated at an interval of plus/minus 10 days for JJI and NPM signals received in Yuzhno-Kurilsk, and meteorological parameters from the local weather-station.

The cross-covariance is a function of three variables, the starting element of the first section, the starting element of the second section, and the length of the sections:

$C_{X Y}(i, j, T)=E\left\{\left(X_{T i}-\mu_{X T i}\right)\left(Y_{T j}-\mu_{Y T i}\right)\right\}$,

where $X_{T i}$ is the sub-sequence of $X$ with a mean over the section of $\mu_{X T i}, Y_{T j}$ is the sub-sequence of $Y$ with a mean over the section of $\mu_{Y T i}$, and $E\{\}$ is the expectation value operator.

It is found that the correlation with pressure, wind velocity and humidity is about $20-25 \%$ and is weaker for temperature (12-15\%). The correlation is positive for pressure and negative for other parameters, which demonstrates the dominating influence of winter cyclones on our results. Any external forcing on the ionosphere both from above (except $\mathrm{X}$-rays) and from below cause negative nighttime amplitude anomalies. The winter cyclones bring about a sharp decrease in pressure and an increase in wind, humidity and temperature (thaw) that determines the type of the correlation with the signals.

Figure 3 shows an example of the anomalies observed in the amplitude of the signals recorded in the PTK station during two cyclones in January 2013. A strong cyclone from the Pacific Ocean approached the Kamchatka Peninsula on 16 January 2013. It reached its peak intensity on 18 January with winds about $22 \mathrm{~m} \mathrm{~s}^{-1}$. A thaw of up to $3{ }^{\circ} \mathrm{C}$ and heavy snowstorm accompanied the cyclone, and the cyclone affected the peninsula for 4 days until 20 January. During this period an evident decrease in the amplitude of the VLF/LF signals was observed with a minimum on 18 January. The second weaker cyclone came up to Petropavlovsk-Kamchatsky a week later (27-29 January) and a moderate decrease in the signal amplitude was also seen at that time. 


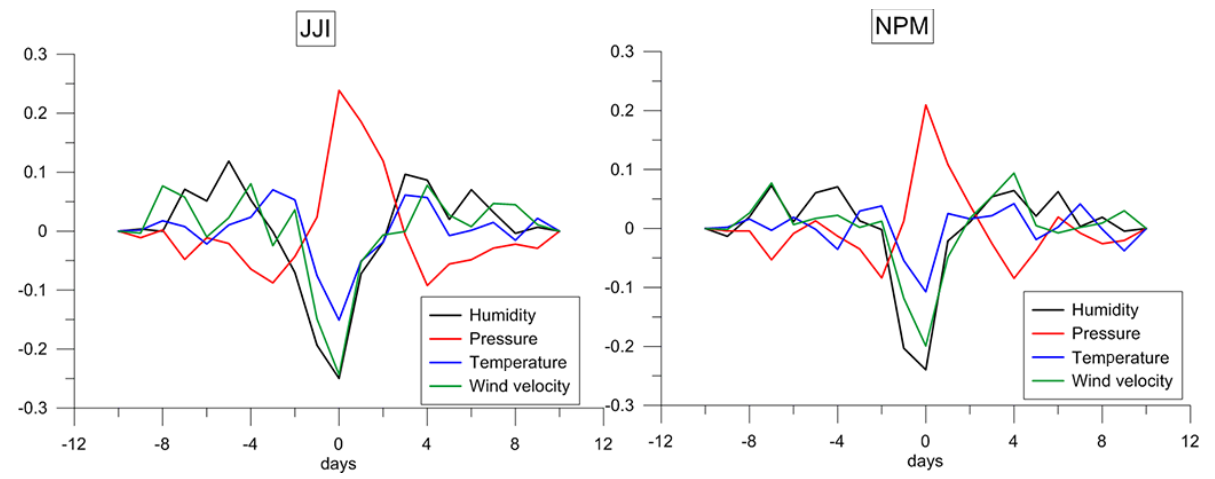

Figure 2. Cross-covariance functions for the average residual amplitude at nighttime of the JJI signal (left) and NPM signal (right) received in Yuzhno-Kurilsk, and meteorological parameters from the local weather station during 2012. The ordinate ( $y$ axis) is the correlation coefficient.

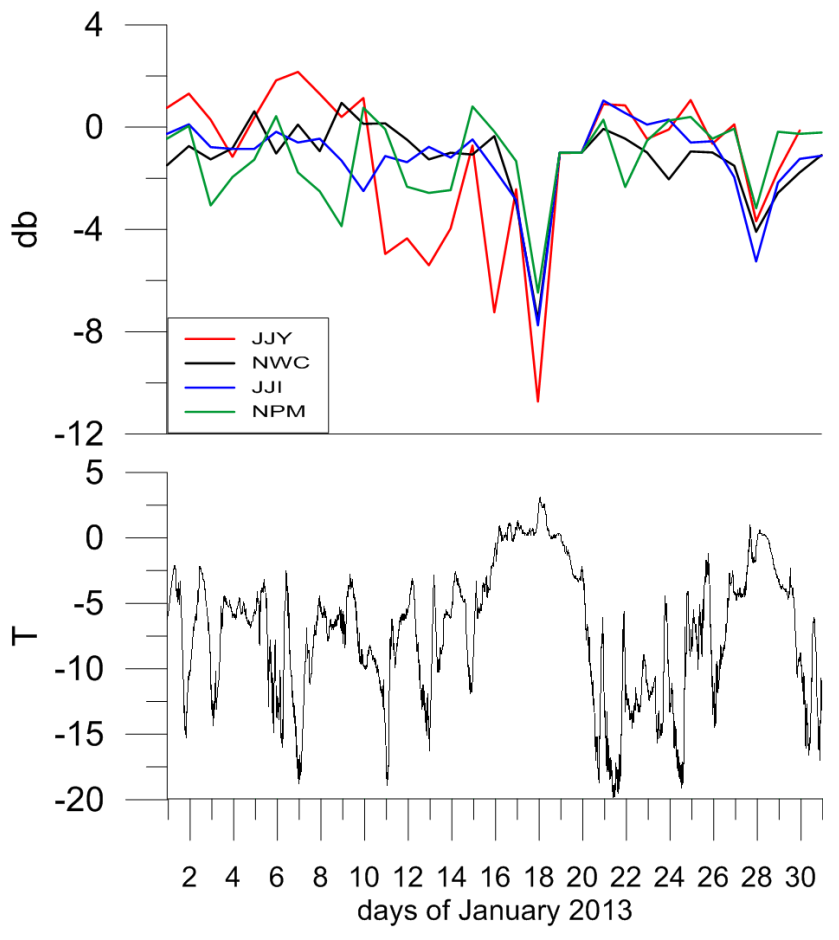

Figure 3. An example of the anomalies observed in the amplitude of the signals recorded at the PTK station during two cyclones in January 2013. The top panel shows the average residual amplitude of VLF/LF signals at nighttime, while the bottom panel refers to the temperature $\left({ }^{\circ} \mathrm{C}\right)$.

The results of analysis show that VLF/LF signals are sensitive to a change in atmosphere parameters. The correlation we found is even better than that with magnetic activity for the same wave paths. However, the characteristics of correlation with the weather to some extent depend on the relative position of receiver and transmitter, the frequency of a signal and specifics of weather conditions in the place of receiving station. The station most sensitive to any variations of atmosphere parameters was found to be situated in $\mathrm{Ku}$ nashir Island just on the coast of Pacific Ocean. The Kuril Islands are characterized by high cyclonic activity and extremely variable weather, with a sharp change of all parameters. Of course, VLF/LF signals propagate over thousands of kilometres from a transmitter to the receiver and any change of weather along this path can influence the signal parameters. In our analysis we took into consideration only weather conditions in the places of receiving stations. For more thorough analysis we need weather data in different points of paths that are not always feasible because (as is seen from Fig. 1) the signals for the most part propagate over the ocean. Such information is available for tropical cyclones, which are very active in the region under consideration.

\subsection{Effects from TCs}

To study the influence of TCs on the VLF/LF signal propagation we use the data from the Japan Meteorological Agency (http://www.jma.go.jp/jma/indexe.html). A majority of the TCs pass southward of Japan and cross wave paths from the NWC transmitter, but some of them move up to Japan and even Kamchatka. We selected eight TCs with different intensities, two of them passing over Japan and six passing in low latitudes. The TCs were selected for intervals with quiet geomagnetic conditions in order to be sure of the reliability of results. The problem of the separation of effects between a magnetic storm and a TC is considered in Afraimovich et al. (2008). Another condition in the selection of TCs and intervals of analysis is connected with very strong seismic activity in the Kuril-Kamchatka, Japan and Southeast Asia regions. This fact was the reason why we have developed the network of VLF/LF stations in this region. So, to avoid the possible influence of other factors, we analyse our data during an interval of about 2 weeks (except for Fig. 7). It is long enough to find typhoon-induced anomalies in the signals because, as a rule, it takes 1-3 days for a TC to cross the sensitivity zones (fifth Fresnel zones) of paths under analysis. 

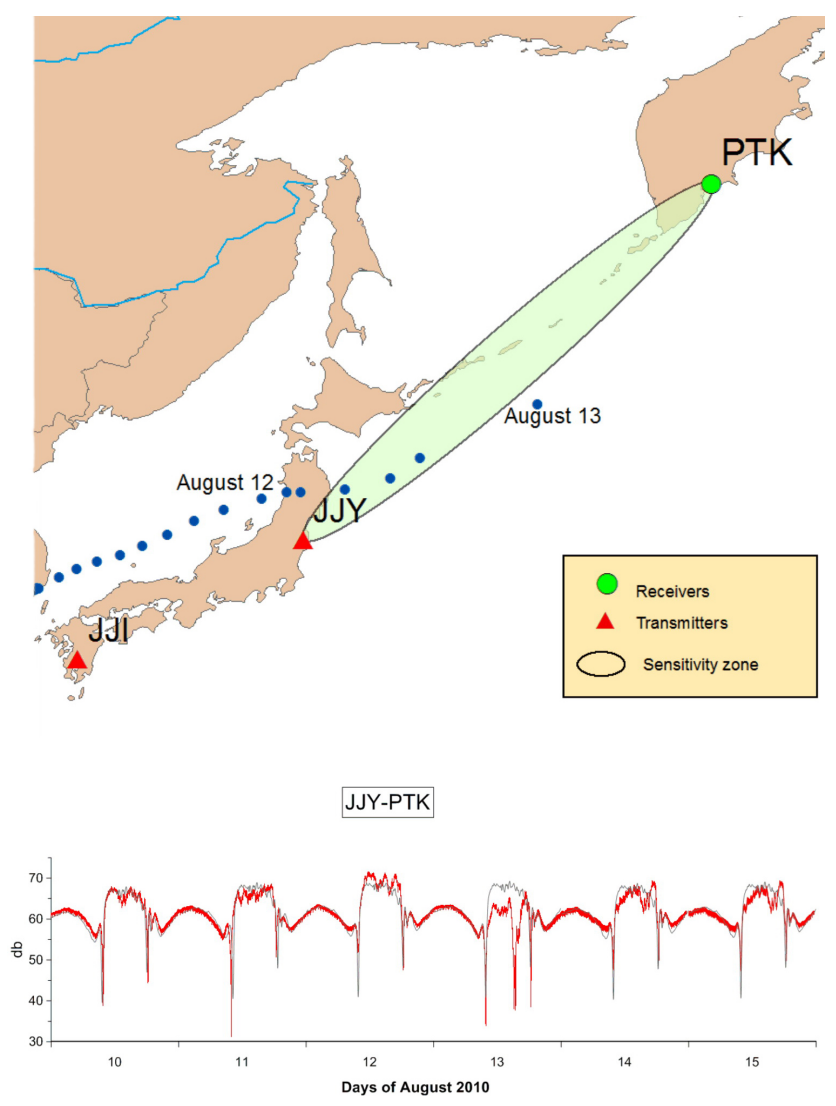

Figure 4. The bottom panel shows an example of anomaly in the JJY signal recorded at the PTK station during the passage of the TC Dianmu (1004). Red and black lines are the observed and averaged signals, respectively. Blue solid circles in the top panel illustrate the position of the TC centres on 12-13 August 2010.

Figures 4-7 illustrate only the centres of TCs, but TCs have a radius of several hundred kilometres, and they can influence VLF/LF signals approaching the wave path sensitivity zone or leaving it. Below we provide results of case study analysis of TC effects on the VLF/LF signals.

TC Dianmu (1004) formed as a tropical depression (TD) south of the Okinawa Islands on 7 August 2010. It made landfall in the northern part of Honshu on 12 August with tropical storm (TS) intensity and transformed into an extratropical cyclone south of Hokkaido that day when it began to cross the sensitivity zone of the JJY-PTK path. Dianmu remained an extratropical cyclone until 13 August. Figure 4 illustrates the TC movement during 12-13 August, the sensitivity zone of the JJY-PTK path and the amplitude of the JJY signal recorded in the PTK station during the period 10-15 August. Red and black lines in the figure are the observed and averaged signals, respectively. A strong decrease in the amplitude (about $20 \mathrm{~dB}$ ) is observed at nighttime on 13 August, but unfortunately, the JJI transmitter had some interruptions in operation during this period so that we cannot compare its data with JJY results.

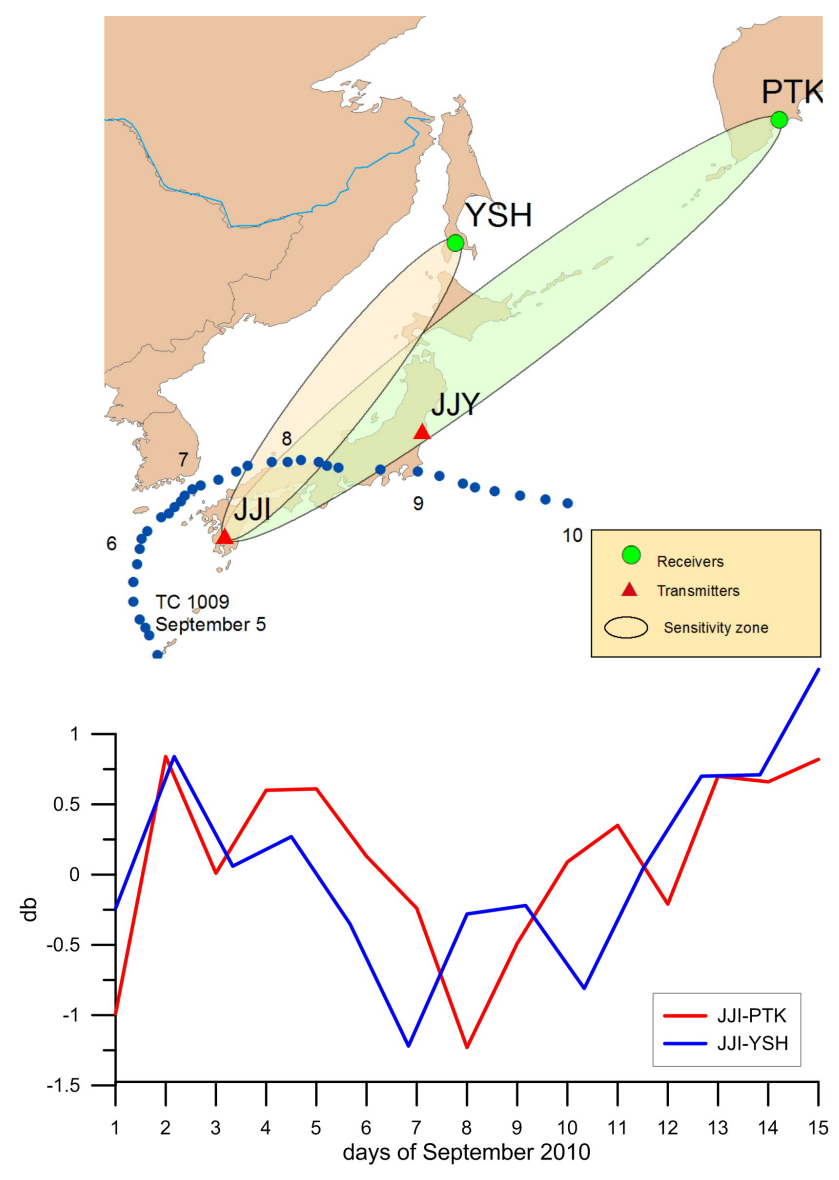

Figure 5. The anomalies in the JJI signal recorded at the PTK and YSH stations during the passage of the TC Malou (1009). Blue solid circles in the top panel show the position of the TC centres on 5-10 September 2010.

Figure 5 shows the anomalies in the JJI signal recorded in the PTK and YSH stations during the passage of another TC Malou (1009). The average residual amplitude of VLF signals in nighttime is shown in this and the next figures. Malou was formed as a TD west of Saipan Island on 1 September 2010. It reached its peak intensity with maximum sustained winds of $50 \mathrm{kt}\left(25 \mathrm{~m} \mathrm{~s}^{-1}\right)$ and a central pressure of $992 \mathrm{hPa}$ in the East China Sea on 5 September. Malou crossed Tsushima Island early on 7 September and then made landfall in Japan just before weakening to TD intensity the next day. It moved across Japan that day and then dissipated east of Japan on 10 September. The decrease in the amplitude of the JJI-YSH and JJI-PTK paths is observed on 7 and 8 September, respectively, when the TC crossed their sensitivity zones.

The next two TCs shown in Fig. 6 passed across the three wave paths: NWS-PTK, NWC-YUK and NWS-YSH in July and August 2013. The TC Soulik (1307) was generated as a TD northwest of the on 7 July 2013, and it was upgraded to TS intensity the next day. Soulik was upgraded to severe tropical storm (STS) intensity $12 \mathrm{~h}$ later and it was upgraded 

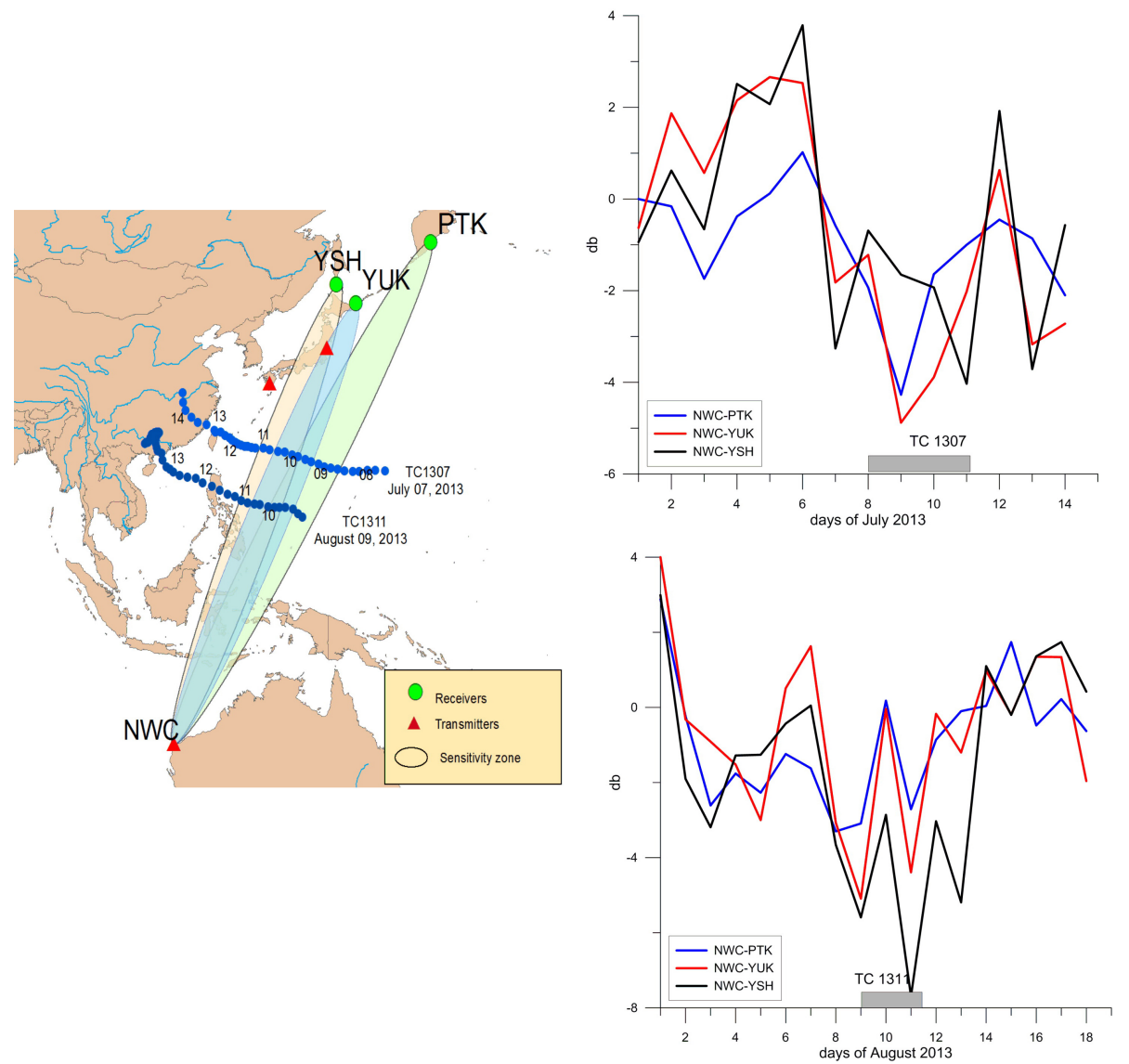

Figure 6. The anomalies in the NWC signal recorded at three stations during the passage of the TC Soulik (1307) (the top right panel), and the TC Utor (1311) (the bottom right panel). Horizontal grey bars on the abscissa show the periods when the TCs crossed the sensitivity zones of the paths under consideration. The positions of the TCs centres are shown in the left panel.

to typhoon (TY) intensity on 9 July. It reached its peak intensity with maximum sustained winds of $100 \mathrm{kt}\left(51 \mathrm{~m} \mathrm{~s}^{-1}\right)$ and a central pressure of $925 \mathrm{hPa}$ on 10 July. Soulik remained with this intensity throughout the next day. The TC moved across sensitivity zones of the three paths from 8 July (NWC-PTK) to 11 July (NWC-YSH). The decrease in the NWC signal recorded in the PTK station is observed on 9 July, when the TC moved across the sensitivity zone of this path. Negative anomalies in the NWC signal recorded at the YUK station were detected on 9 and 10 July during the TC movement to the west and on the next day we could observe a decrease in the NWS signal recorded at the YSH station.

The TC Utor (1311) formed as a TD northwest of Caroline Islands on 8 August 2013, and was upgraded to TS intensity the next day. Utor was upgraded to TY intensity on 10 August and it reached its peak intensity with maximum sustained winds of $100 \mathrm{kt}\left(51 \mathrm{~m} \mathrm{~s}^{-1}\right)$ and a central pressure of $925 \mathrm{hPa}$ on 11 August. The TC moved across sensitivity zones of the three paths from 9 to 11 August. The decrease of the signals in YSH and YUK stations is noticeable on 9 and 11 August. A maximum anomaly is obvious in the NWC-YSH path on 11 August, when the TC moved inside the sensitivity zone of this path. But the effect in the signal propagating along the NWC-PTK path is weaker.

The last period selected for our analysis is August 2012, when four TCs with different intensity formed in the South Asia region and moved across the paths under consideration. The receiver in PTK was temporally out of operation during this period, so that we analysed the signals on two paths. The interval of analysis was from 23 July to $31 \mathrm{Au}-$ gust. During this period three strong earthquakes occurred, with the epicentres inside the sensitivity zones of our paths on 18 August $(M=6.3), 26$ August $(M=6.6)$ and $31 \mathrm{Au}-$ gust ( $M=7.6$ ). The first TC Damrey (1210) in the interval of analysis was formed as a TD west of Minamitorishima Island on 27 July 2012, and it was upgraded to TS intensity the next day. Damrey was upgraded to STS intensity on 30 July and it was upgraded to TY intensity over the Yellow Sea the next day; it reached its peak intensity with maximum sustained winds of $70 \mathrm{kt}\left(36 \mathrm{~m} \mathrm{~s}^{-1}\right)$ and a central pressure of $965 \mathrm{hPa}$. This TC entered the sensitivity zone of the path NWC-YUK on 30 July and moved across the paths under consideration until 1 August. Following Damrey, another TC Haikui (1211) was formed on 1 August. It was upgraded to TS intensity 

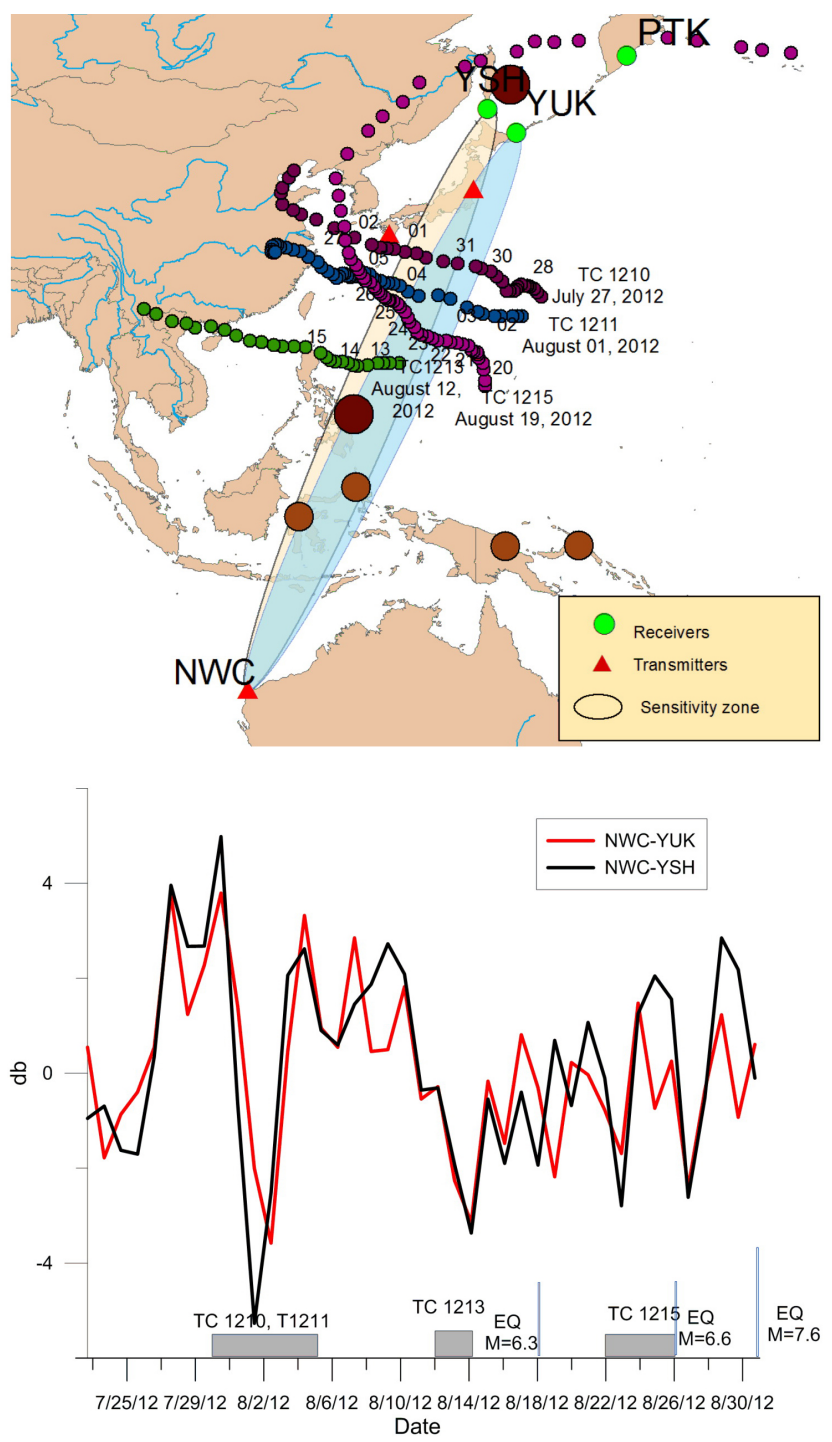

Figure 7. The anomalies in the NWC signal recorded at the YSH and YUK stations during the passage of several TCs in August 2012 (the bottom panel). Horizontal grey bars on the abscissa show the periods when the TCs crossed the sensitivity zones of the paths under consideration, and blue vertical bars refer to the times of the earthquake occurrences. The epicentres of earthquake with $M>6$, which took place in the Pacific region during the period of analysis, are shown in the top panel by large solid brown circles.

on 3 August and then Haikui was upgraded to STS intensity northwest of Okinawa Island on 5 August. It was upgraded to TY intensity and reached its peak intensity with maximum sustained winds of $65 \mathrm{kt}\left(33 \mathrm{~m} \mathrm{~s}^{-1}\right)$ and a central pressure of $965 \mathrm{hPa}$ on 7 August. Haikui moved across the NWC-YUK and NWC-YSH sensitivity paths from 3 to 5 August. The TC 1210 apparently caused a decrease in the signal on the path NWC-YSH observed on 1 August. The decrease in the signal on the path NWC-YUK on 2 August, is most likely to be under the influence of the TC 1211.
The TC Kai-tak (1213) was generated as a TD east of the Philippines, which is inside sensitivity zones of the paths under analysis, on 12 August. It was upgraded to TS intensity on 13 August and it left the sensitivity zones on 14 August before reaching its peak intensity. The decrease of the signals on both paths on 14 August can be due to the TC influence or it can be a preseismic effect before the earthquake on $18 \mathrm{Au}-$ gust. The next very strong TC Bolaven (1215) was formed as a TD west of the Mariana Islands on 19 August and was upgraded to TS intensity $24 \mathrm{~h}$ later. It was then upgraded to TY intensity on 21 August. Bolaven reached its peak intensity with maximum sustained winds of $100 \mathrm{kt}\left(51 \mathrm{~m} \mathrm{~s}^{-1}\right)$ and with central pressure of $910 \mathrm{hPa}$ on 25 August. It passed around Okinawa Island with TY intensity the next day. The typhoon moved across the sensitivity zones of our wave paths from 22 to 26 August in its peak intensity. Nevertheless, it seems that this TC did not have significant influence, if any, on the VLF signal. Some decrease in the signal on both paths can be seen on 22 August and 26 August, but we are not sure that this decrease is unambiguously related to the TC because of the occurrence of two earthquakes on 26 and 31 August.

We made an analysis of the spectral composition of the VLF/LF signals for typhoon-induced disturbed days. For the analysis we used the filtered $(0.2-15 \mathrm{mHz})$ nighttime amplitudes and phases of the signals. Some examples are given in Fig. 8. The figure illustrates the wavelet spectra of the JJY signal recorded at the PTK station on 13 August 2010 (TC 1004) and the NWC signal recorded at the YSH station on 1 August 2012 (TC 1210) and 11 August 2013 (TC 1311). The anomalies in the VLF/LF signals observed on these days can be caused only by TCs activity. The maximum of spectral energy both in the phase and amplitude of the JJY signal is in the interval $1-2.5 \mathrm{mHz}$ (i.e. periods of about $7-16 \mathrm{~min}$ ). The maximum in the fluctuation spectra of the NWC signal on two disturbed days is in the range of periods of about 15$55 \mathrm{~min}$. These periods found in the TC-disturbed days correspond to the range of periods for IGWs.

\section{Conclusions}

Perturbations of the VLF/LF signals associated with meteorological factors were investigated in this work. The correlation analysis made for four VLF/LF transmitter signals in the frequency range of $\sim 20-40 \mathrm{kHz}$ recorded in three receiving stations in the Far East region has shown that VLF/LF signals are sensitive to any change of atmosphere parameters (pressure, humidity, wind velocity and temperature). However, the characteristics of correlation with weather depend on the relative position of receiver and transmitter, frequency of a signal and specifics of weather conditions in the place of receiving station. The station exhibiting the highest sensitivity to variations of atmosphere parameters was found to be the one situated in Kunashir Island. 
August 13, 2010 JJY-PTK
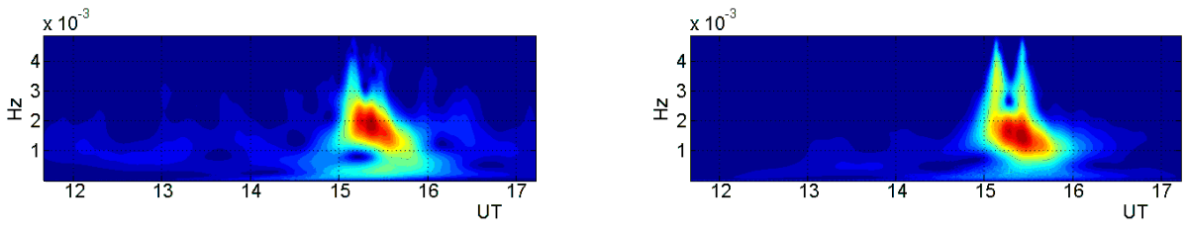

August 01, 2012 NWC-YSH
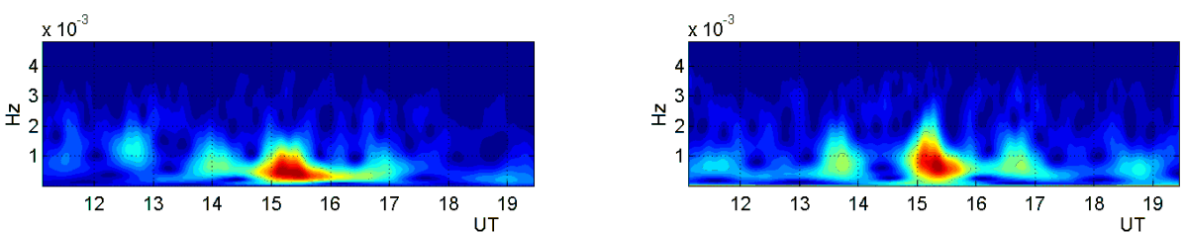

August 11, 2013
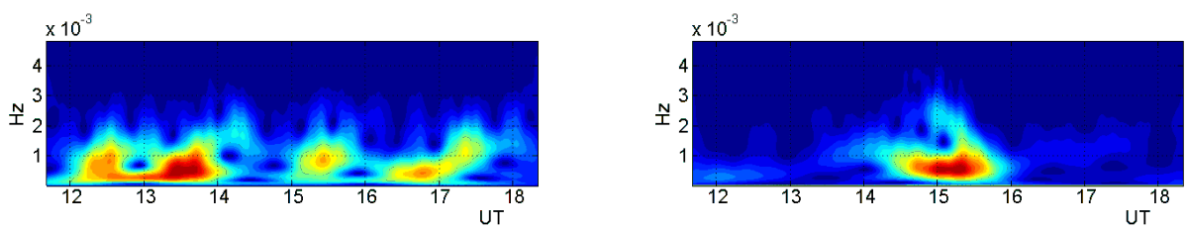

Figure 8. Examples of the wavelet spectra of the filtered $(0.2-15 \mathrm{mHz})$ typhoon-induced disturbed amplitudes (left) and phases (right) of the VLF/LF signals.

For the first time, we performed a detailed analysis of the VLF/LF signals sensitivity to TCs, in which eight TCs of different intensity passing across the VLF/LF signal wave paths were considered. Negative nighttime anomalies in the signal amplitude that are most probably caused by TC activity have been found for the six events. Those anomalies were observed during 1-2 days when TCs moved inside the sensitivity zones of the subionospheric paths. In two cases (TC 1213 and TC 1215) we could not establish the cause of the signal decrease, because it can be due to either the TCs influence or seismic activity. The spectral composition of the TCdisturbed signals is very close to the spectral composition of seismo-disturbed days (Rozhnoi et al., 2012). Our spectral analysis, made for the typhoon-induced disturbed VLF/LF signals, revealed the maximum of fluctuation spectral energy in the interval periods of about 7-16 and 15-55 min that corresponds to the range of IGW periods. This result corroborates the theory of penetration into the lower ionosphere the typhoon-generated IGWs.

We have not found any direct correlation between the TC intensity and magnitude of the signal anomalies.

Acknowledgements. The work was supported by a joint United Kingdom-Russia project under grant 13-05-92602 KO_a and under grant RFBR 14-05-00099.

Edited by: G. Panegrossi

Reviewed by: S. K. Chakrabarti and three anonymous referees

\section{References}

Afraimovich, E. L., Voeykov, S. V., Ishin, A. B., Perevalova, N. P., and Ruzhin, Y. Y.: Variations in the total electron content during a powerful typhoon of August 5-11, 2006, near the Southeastern Coast of China, Geomagn. Aeronnomy, 48, 703-708, 2008.

Bauer, S. J.: An apparent ionospheric response to the passage of hurricanes, J. Geophys. Res., 63, 265-269, 1958.

Bishop, R. L. and Straus, P. R.: Characterizing ionospheric variations in the vicinity of hurricanes and typhoons using GPS occultation measurements, AGU Fall Meeting (San Francisco, Dec. 11-15, 2006); EOS Transactions, American Geophysical Union, 87, Suppl. Report No. SA33B-0276, 2006.

Bondur, V. G. and Pulinets, S. A.: Effect of mesoscale atmospheric vortex processes on the upper atmosphere and ionosphere of the Earth, Izvestiya, Atmospheric and Oceanic Physics, 48, 871878, 2012.

Bondur, V. G., Pulinets, S. A., and Uzunov, D.: Ionospheric effect of large-scale atmospheric vortex by the examle of Hurricane Katrina, Issledovaniya Zemli iz kosmosa (Study of the Earth from the space), 6, 3-11, 2008 (in Russian).

Dhaka, S. K., Takahash, I. M., Shibagaki, Y., Yamanaka, M. D., and Fukao, S.: Gravity wave generation in the lower stratosphere due to passage of the typhoon 9426 (Orchid) observed by the MU radar at Shigaraki $\left(34.85^{\circ} \mathrm{N}, 136.10^{\circ} \mathrm{E}\right)$, J. Geophys. Res., 108, 4595, doi:10.1029/2003JD003489, 2003.

Hayakawa, M., Horie, T., Yoshida, M., Kasahara, Y., Muto, F., Ohta, K., and Nakamura, T.: On the ionospheric perturbation associated with the 2007 Niigata Chuetsu-oki earthquake, as seen from subionospheric VLF/LF network observations, Nat. Hazards Earth Syst. Sci., 8, 573-576, doi:10.5194/nhess-8-5732008, 2008. 
Huang, Y. N., Cheng, K., and Chen, S. W.: On the detection of acoustic-gravity waves generated by typhoon by use of real time HF Doppler frequency shift sounding system, Radio Sci., 20, 897-906, doi:10.1029/RS020i004p00897, 1985.

Isaev, N. V., Sorokin. V. M., Chmyrev. V. M., and Serebryakova, O. N.: Ionospheric electric fields related to sea storms and typhoons, Geomagnetism and Aeronomy, 42, 638-643, 2002.

Isaev, N. V., Kostin, V. M., Belyaev, G. G., Ovcharenko, O. Ya., and Trushkina, E. P.: Disturbances of the topside ionosphere caused by typhoons, Geomagnetism and Aeronomy, 50, 243-255, 2012.

Kazimirovsky, E.: Coupling from below as a source of ionospheric variability: A review, Ann. Geophys., 45, 1-29, 2002, http://www.ann-geophys.net/45/1/2002/.

Lin, J. W.: Study of ionospheric anomalies due to impact of typhoon using Principal Component Analysis and image processing, J. Earth Syst. Sci., 121, 1001-1010, 2012.

Liu, Y. M, Wang, J. S., and Suo, Y. C.: Effects of typhoon on the ionosphere, Adv. Geosci., 29, 351-360, 2006, http://www.adv-geosci.net/29/351/2006/.

Mao, T., Wang, J. S., Yang, G. L., Yu, T., Ping, J. S., and Suo, Y. C.: Effects of typhoon Matsa on ionospheric TEC, Chinese Science, 55, 712-717, doi:10.1007/s11434-009-0472-0, 2010.

Mikhailova, G. A., Mikhailov, Y. M., and Kapustina, O. V.: ULFVLF electric fields in the external ionosphere over powerful typhoons in Pacific Ocean, Geomagnetism and Aeronomy, 2, 153 $158,2000$.

Perevalova, N. P. and Polekh, N. M.: An investigation of the upper atmosphere response to cyclones using ionosonde data in Eastern Siberia and the Far East. Proc. SPIE 7296, Fifteenth International Symposium on Atmospheric and Ocean Optics/Atmospheric Physics, 72960J, doi:10.1117/12.823814, 2009.

Polyakova, A. S. and Perevalova, N. P.: Investigation into impact of tropical cyclones on the ionosphere using GPS sounding and NCEP/NCAR Reanalysis data, Adv. Space Res., 48, 1196-1210, 2011

Pulinets, S. A., Boyarchuk, K. A., Hegai, V. V., Kim, V. P., and Lomonosov, A. M.: Quasielectrostatic model of atmospherethermosphere-ionosphere coupling, Adv. Space Res., 26, 12091218, 2000.

Rozhnoi, A. A., Solovieva, M. S., Molchanov O. A., Hayakawa, M., Maekawa, S., and Biagi, P. F.: Sensitivity of LF signal to global ionosphere and atmosphere perturbations in the network of stations, Phys. Chem. Earth, 1, 409-415, 2006.
Rozhnoi, A., Solovieva, M., Biagi, P. F., Schwingenschuh, K., and Hayakawa, M.: Low frequency signal spectrum analysis for strong earthquakes, Ann. Geophysics, 55, 181-186, doi:10.4401/ag-5076, 2012.

Sharkov, E. A.: Global Tropical Cyclogenesis, Springer Praxis Books, 604 pp., 2012.

Shen, C. S.: The correlations between the typhoon and the FoF2 of ionosphere, Chinese J. Space Sci., 2, 335-340, 1982 (in Chinese).

Sorokin, V. M., Yaschenko, A. K., Chmyrev, V. M., and Hayakawa, M.: DC electric field formation in the mid-latitude ionosphere over typhoon and earthquake regions, Physics and Chemistry of the Earth, 31, 454-461, 2006.

Tao, Y., Wang, Y. G., Mao, T., Wang, J. S., Wang, S. Y., Shuai, F. H., Su, W. D., and Li, J. T.: A case study of the variation of ionospheric parameter during typhoons at Xiamen, Acta Meteorol Sin., 4, 569-576, 2010.

Vanina-Dart, L. B., Romanov, A. A., and Sharkov, E. A.: Influence of a tropical cyclone on the upper ionosphere according to tomography sounding data over Sakhalin Island in November 2007, Geomagnetism and Aeronomy, 51, 774-782, 2011.

Xiao, S. G., Zhang, D. G., and Xiao, Z.: Study on the detectability of typhoon-generated acoustic-gravity waves, Chinese Journal of Space Science, 27, 35-40, 2007.

Xiao, S. G., Shi, J. K., Zhang, D. H., Hao, Y. Q., and Huang, W. Q.: Observational study of daytime ionospheric irregularities associated with typhoon, Science China Technological Sciences, 55, 1302-1304, doi:10.1007/s11431-012-4816-7, 2012.

Xiao, Z., Xiao, S. G., Hao, Y. Q., and Zhang, D. H.: Morphological features of ionospheric response to typhoon, J. Geophys. Res. Space Physics, 112, A04304, doi:10.1029/2006JA011671, 2007.

$\mathrm{Xu}$, G., Wan, W., She, C., and Du, L.: The relationship between ionospheric total electron content (TEC) over East Asia and the tropospheric circulation around the Qinghai-Tibet Plateau obtained with a partial correlation method, Adv. Space Res., 42, 219-223, 2008.

Zakharov, V. I. and Kunitsyn, V. E.: Regional features of atmospheric manifestations of tropical cyclones according to groundbased GPS network data, Geomagnetism and Aeronomy, 52, 533-545, doi:10.1134/S0016793212040160, 2012. 